\title{
Early Outcome of Liver Resections in Octogenarians
}

\section{Bhandari RS, ${ }^{1}$ Riddiough $G,{ }^{2}$ Muralidharan V, ${ }^{2}$ Christophi $C^{2}$}

\author{
${ }^{1}$ Department of Surgery, \\ Tribhuvan University Teaching Hospital. \\ ${ }^{2}$ Department of Surgery, \\ Austin Health, Royal Melbourne University
}

\section{Corresponding Author}

Ramesh Singh Bhandari,

Department of Surgery,

Tribhuvan University Teaching Hospital.

E-mail: rsbhandari09@gmail.com

Citation

Bhandari RS, Riddiough G, Muralidharan V, Christophi C. Early Outcome of Liver Resections in Octogenarians. Kathmandu Univ Med J 2015;49(1):19-23.

\section{ABSTRACT}

\section{Background}

Reports on safety and feasibility of liver resection in patients 80 years and older are very limited.

\section{Objective}

Here, we intend to analyze the perioperative outcomes of liver resections in octogenarians performed at a single tertiary level teaching hospital over a ten years period.

\section{Method}

Retrospective review of the medical records (between 2004 to 2014) of patients of the defined age group was performed. Clinicopathological features, indications, extent of resections, intraoperative parameters, postoperative complications and final outcome were analyzed. Findings were compared with similar studies published in literature.

\section{Result}

Total 19 (11 male, 8 female, maximum age 85 years) patients of the study group underwent liver resection during the defined period. Commonest indication was colorectal liver metastasis (9 patients). One patient had pancreaticodudenectomy for periampullary malignancy four years prior to present with liver metastasis and subsequently had liver resection for recurrence of disease. Except one, all had open surgery. Types of resection ranged from sub segmental to major right (8 patients) and left ( 1 patient) hepatectomy. Total $3(27 \%)$ out of 11 patients on whom drain was not placed required radiological drainage of abdominal collection. One patient developed liver abscess postoperatively and was also successfully drained under radiological guidance. Only 2 (10.5\%) had prolonged Intensive Care Unit (ICU) stay and remaining patients were discharged to ward after $24 \mathrm{hrs}$ of observation in high dependency/Intensive care unit. Median hospital stay was 11 days. Postoperative complications were 3 of grade II, 4 of grade IIla, 1 of IIIb and 2 of IVa. Total 9 patients were discharged to rehabilitation centers and remaining 10 could be discharged home. There was $0 \%$ mortality.

\section{Conclusion}

In appropriately selected cases, when performed in specialized tertiary centers excellent perioperative outcomes of liver resections can be achieved even in patients of 80 years of age and above.

\section{KEY WORDS}

Elderly, liver, morbidity, mortality, octogenarians, resection 


\section{INTRODUCTION}

Liver resections remain the treatment of choice for large range of primary and secondary liver tumors. Due to the significant improvement in surgical techniques and perioperative management, liver resections are routinely performed in tertiary level centers with low morbidity and mortality. ${ }^{1,2}$ Safety and feasibility of liver resections in elderly population has been studied and widely published. ${ }^{3}$ Except few, most of the reports have demonstrated a very good perioperative outcome even for the elderly group of population. However, point to be noticed is that most of these reports have considered old age cut off as 65 or 70 years and some up to 75 years., ${ }^{3,4}$ Reports on liver resection in octogenarians are very limited. In this study of ours, we intend to analyze perioperative outcomes of liver resections performed in patients 80 years and older.

\section{METHODS}

A review of the prospectively maintained database of patients undergoing liver resections between 2004 and 2014 at the hepatopancreatobiliary and liver transplant unit of Austin hospital was performed. Austin hospital, Melbourne is a tertiary teaching and referral hospital with a dedicated unit for liver, pancreas, biliary tract and liver transplant surgery. Patients 80 years and older undergoing liver resections, including both major and minor and for any defined indications were included for the study. Every patient in the series had undergone thorough medical and preoperative anaesthetic assessment. Detail cardiac and respiratory function assessment including others were carried out as required during preoperative assessment. Similarly, prior to the surgery, management plans were discussed in the weekly multidisciplinary meetings. All the surgical operations were performed by the expert hepatobiliary surgeons of the unit having various years of working experience as a consultant surgeon and assisted by fellows and trainee surgeons in various stages of training. Because of the retrospective nature of our study, we do not have data on how many patients were contra indicated to undergo surgery or not referred to the unit by the general practitioners and the oncologist because of the advanced age.

The Brisbane 2000 terminology for liver anatomy and resections was used to define the extent and type of liver resections performed. ${ }^{5}$ Three or more anatomical segment resection was considered as major and any resections less than that was described as minor liver resection. Similarly, Clavien-Dindo grading system for classification of the surgical complications was used to grade the postoperative complications. ${ }^{6}$ This included both medical and surgical complications. Any complications or deaths that occurred with in 30 days after operation or with in same hospital admissions were defined as operative morbidity and mortality. As multiple surgeons were involved in surgery in this series, there were minor differences in the technique used. To mention few, the type of incision used, parenchymal transaction technique, use of inflow control and use of drain varied according to the surgeons preference. However, preoperative work up, use of prophylactic antibiotic, Deep Venous Thrombosis prophylaxis and postoperative management were similar. The unit follows the common guideline on postoperative management of liver resections. Postoperatively, all the patients were managed in high dependency or intensive care unit and transferred to ward when stable.

Primary endpoint of the study was to analyze the perioperative mortality and morbidity defined as above. Similarly, secondary parameters analyzed were sex distribution, classification of patients by ASA system, indications, extent of resections, use of inflow control, use of abdominal drains, postoperative management and final outcome. Subgroup analysis of complications between major and minor liver resections was also performed. Overall postoperative complications and mortality were then compared with the similar studies published in the literature.

\section{RESULTS}

During the 10 years of the study period, the unit performed a total of 506 liver resections. Total 19 patients were of the study group i.e. patients 80 years and older, thus comprised $3.75 \%$ of total liver resections. The maximum age undergoing liver resection was 85 years and this patient underwent liver resection for colorectal liver metastasis. Patients were preoperatively classified according to ASA classification and patients in our series were ASA II- 2 and ASA III- 17. Thus, none of the study group patients in our series were Class 4 or above.

The most common indication was colorectal liver metastasis (9 of 19). Among the indications included in others (as in Table 1), were left intrahepatic cholangiocarcinoma 1, metastatic melanoma 2, gallbladder carcinoma 1 and also included a patient with recurrence in right liver following a pancreaticodudenectomy for a periampullary malignancy, four years prior to the presentation with liver metastasis. This patient subsequently underwent a successful right hepatectomy. Benign indications included one nonspecific liver nodule (on histology was chronic liver abscess) and other symptomatic hemangioma. Out of the 9 major liver resections, 8 were right hepatectomy and 1 left hepatectomy. Minor resections included all different types, left later sectionectomy 2, other bisegmentectomies 2, segmental and sub segmental resections 4 . So, in our series we had similar number of major and minor resections.

Except one patient in the series, the entire patient had open liver resections. One patient, who was undergoing a laparoscopic liver resection, had a nonspecific liver nodule. The nodule was also resected laparoscopically in the form 
Table 1. Preoperative parameters, indication and type of resection

\begin{tabular}{lc|}
\hline Variables & $\boldsymbol{\eta}$ (Total= 19) \\
\hline Sex distribution & \\
\hline Male & 11 \\
\hline Female & 8 \\
\hline ASA classification & \\
\hline ASA 2 & 2 \\
\hline ASA 3 & 17 \\
\hline Indication & \\
\hline Colorectal liver metastasis & 9 \\
\hline Hepatoma & 3 \\
\hline Other malignancies & 5 \\
\hline Benign disease & 2 \\
\hline Type of resection & \\
\hline Major Hepatectomy & 9 \\
\hline Minor Hepatectomy & 10 \\
\hline
\end{tabular}

of sub segmental liver resection and on histopathology turned out to be a chronic liver abscess. The inflow control during parenchymal transection was not a routine practice. Only in 8 of the patient, extra hepatic non-selective inflow control was used during the transection. Similarly the abdominal drain was not used routinely. However, 3 of 10 patients who did not have drain developed postoperative complications. Two had abdominal collection requiring radiological drainage while one patient had bile leak and required a biliary stent. One patient who had a drain placed also developed a liver abscess on follow up and also required a radiological drainage. Subsequently, all of these patients did well and were discharged from the hospital.

Following the surgery, patients were routinely observed in high dependency/intensive care unit and were discharged to a normal ward when stable. Total 17 patients were stable enough to be transferred to ward with in 24 hours of observation while 2 patients required a prolonged intensive care unit stay. One patient developed postoperative confusion and required prolonged intubation. After 10 days of ICU stay, the patient was finally transferred to ward. Similarly, the other patient had rapid AF and oliguria and required ICU management. This patient was then discharged to ward on $7^{\text {th }}$ day. Other postoperative complications included both medical and surgical complications (Table 2). There were no grade I and grade $V$ complications in the series (Table 3 ). Our overall morbidity rate was $52.6 \%$. All of the 19 patients in our series were subsequently discharged from hospital with varying period of hospital stay (median hospital stay of 11 days and maximum stay of 41 days). Total 10 (52.6\%) were able to go home while 9 $(47.4 \%)$ patients required rehabilitation care (Table 4$)$.

We performed a subgroup analysis of postoperative complications between major and minor liver resections. Grade II and IIla were similar in both groups. However, both grade IV complications occurred in patients with major liver resections. One patient had a right hepatectomy for
Table 2. Types of Postoperative Morbidity

\begin{tabular}{lc|}
\hline Complications & $\boldsymbol{\eta}$ (Total= 19) \\
\hline Surgical & \\
\hline Abdominal collection & 2 \\
\hline Bile leak & 1 \\
\hline Pneumothorax & 1 \\
\hline Liver abscess & 1 \\
\hline Medical & \\
\hline Blood transfusion & 2 \\
\hline Pneumonia & 1 \\
\hline Oliguria, Atrial fibrillation & 1 \\
\hline Prolonged intubation & 1 \\
\hline
\end{tabular}

Table 3. Postoperative complications according to grades

\begin{tabular}{|lc|}
\hline Grades & n (Total= 19) \\
\hline Grade I & 0 \\
\hline Grade II & 3 \\
\hline Grade III-a & 4 \\
\hline Grade III-b & 1 \\
\hline Grade IV-a & 2 \\
\hline Grade IV-b & 0 \\
\hline Grade V & 0 \\
\hline
\end{tabular}

Table 4. Overall outcomes

\begin{tabular}{lc|} 
Variables & $\boldsymbol{\eta}$ (Total= 19) \\
\hline Discharged home & $10(52.6 \%)$ \\
\hline Transferred to rehabilitation center & $9(47.4 \%)$ \\
\hline Overall morbidity & $19(52.5 \%)$ \\
Mortality & 0
\end{tabular}

metastatic melanoma while the other one also had a right hepatectomy but for hepatoma. Both of these patients were the ones requiring prolonged intensive care stay.

\section{DISCUSSION}

At the beginning of 21st century, already there were around 600 million elderly people worldwide. ${ }^{4}$ The population has been aging with increasing rate of people aged 80 years and above. ${ }^{4,7}$ Elderly population is now accountable for more than $60 \%$ of all new cancers and $70 \%$ cancer related deaths. ${ }^{8}$ This figures supports the fact that there has been significant expansion of surgical indications in the elderly. Similar situation exists in Australia. According to the Australian Bureau of Statistics, there were around 719.9 thousand people aged 80 years and above. ${ }^{9}$ Liver resections remain the treatment of choice for vast majority of primary and secondary liver lesions. Thus, in days to come there will be increasing demand of liver resections in the elderly population for wide range of indications mostly being metastatic and some being primary liver tumors. Regardless of the indications for the liver resections in the elderly age group, this population is more likely to have cardiac and pulmonary morbidities including others, which 
may be affecting the postoperative outcome. ${ }^{3}$

Large numbers of reports have been published on safety and feasibility of liver resections in elderly. Some of them demonstrated increased postoperative morbidity and mortality rates related to age, while others have been able to produce similar results especially when indications included colorectal liver metastasis and hepatocellular carcinomas. ${ }^{10-14}$ On a recent publication, Sulpice et al performed a retrospective review of 912 liver resections. ${ }^{4}$ Total 152 patients $(15.2 \%)$ in their series were $\geq 75$ years. However, a separate analysis was not performed for octogenarians. While the postoperative complications were similar to the younger age group, there was increased mortality for this elderly group. Alongside with factors like cirrhosis, preoperative embolization, caval vein clamping and intraoperative transfusion, advanced age was an independent risk factor for increased mortality.

Reports regarding the outcome specially focusing on octogenarians undergoing liver resections are very limited. After extensive literature search, only three publications were found in this topic. ${ }^{3,15,16}$ One of the earliest reports was by Wu CC et al from Taiwan. ${ }^{16}$ They published a retrospective review of 21 octogenarians undergoing liver resections for hepatocellular carcinomas. They demonstrated similar morbidity and mortality when compared to the younger population and thus justified the role of liver resections in selected octogenarians. Postoperative complications were $14.3 \%$ for octogenarians and $15.5 \%$ for younger group. Mortality was $0 \%$ and $2.1 \%$ in octogenarians and younger group respectively. Riffat et al from Sydney reported their 15 octogenarians undergoing liver resections for various indications with $47 \%$ overall morbidity. ${ }^{15}$ They had 1 death in their series. Similarly, there was another study published which indeed had a larger octogenarian population in comparison to the two previously mentioned publications. Shirabe et al published reports on 43 octogenarians undergoing liver resections for various indications and compared with 307 patients younger than 80 years. ${ }^{3}$ They demonstrated $0 \%$ mortality for octogenarians and the postoperative morbidity (26\%) and early prognosis was also comparable with younger group. In our study we have also demonstrated $0 \%$ mortality for liver resections in octogenarians. The morbidity in our study was $52.5 \%$, which included both medical and surgical morbidity.

The mortality has been comparable in all of the above studies including ours except some variation in terms of morbidity. Except one patient who belonged to ASA 4 in the series by Riffat et al, rest of the patients in all the studies were ASA 3 and below. The only mortality on all those series was actually the same patient in the series with ASA 4 class who died with cerebrovascular event. ${ }^{15}$ Our median hospital stay (11 days) was also comparable with all the studies on liver resection on octogenarians. One of the significant postoperative surgical complications in our series was postoperative abdominal collection. Two patients had subphrenic and subhepatic collections; one had bile leak and one patient liver abscess at resection site. All of them were successfully treated with nonoperative approach, three were drained with radiological guidance and one had ERCP and stenting. Similar type of complications have been reported by others and treated aggressively with nonoperative approach, tolerated well by the octogenarians.

Operative blood loss during hepatectomy is a known factor that seriously affects the postoperative outcome. ${ }^{17-19}$ Like others, we also paid a significant attention to meticulous approach in order to minimize the blood loss in our patients, which was reflected by need of transfusion in only 2 (10.5\%) of our patients. Selective pedicle clamping (intermittent Pringle maneuver) was used when deemed necessary. Our rates of transfusion have been comparable to the published reports. Shirabe et al reported 19\% transfusion rate and they reported that low transfusion rate was one was one of the main contributing factor to achieve $0 \%$ mortality in their series. ${ }^{3}$ Menon et al demonstrated transfusion of $>3 \mathrm{U}$ as an independent poor prognostic factor of colorectal liver metastasis resection in the elderly patients. ${ }^{10}$

Due to the small number of cases we couldn't make a significant conclusion when major and minor resections were compared in terms of outcome. In our series, major and minor resections were almost similar in number. The two grade 4 complications only occurred with major hepatectomy. However rest of the grades were similar in both the groups. Sulpice et al in their review could demonstrate major hepatectomy, among others as an independent factor contributing to postoperative mortality. ${ }^{4}$ The above-mentioned reports on liver resection on octogenarians did not specifically analyze the correlation between outcome and extent of hepatectomy.

Our study did have few limitations. The most important one being the retrospective nature of our study, only octogenarians who had liver resections were included for analysis and thus we do not actually have data of patients who were denied for surgery. Secondly, this study focuses mainly on perioperative outcome and does not analyze the long-term outcomes. Small sample size was another important limitation of the study. However, from the results we have produced and after reviewing the literature on the similar subjects, we believe our data can be best utilized to demonstrate the early perioperative outcome of liver resections in patients with 80 years and older.

\section{CONCLUSION}

In conclusion, the published reports in elderly and specially the one highlighting the liver resections in octogenarians demonstrate the safety and feasibility of liver resections in selected group of patients of 80 years and older. Our results further supports this finding and stresses on the fact that liver resections can be performed on octogenarians in specialized and tertiary centers with very low morbidity and mortality. 


\section{REFERENCES}

1. Jarnagin $W R$, Gonen $M$, Fong $Y$, DeMatteo RP, Ben-Porat $L$ et al. Improvement in perioperative outcome after hepatic resection: analysis of 1,803 consecutive cases over the past decade. Ann Surg. 2002;236:397-406.

2. Poon RT, Fan ST, Lo CM, Liu CL, Lam CM, Yuen WK et al. Improving perioperative out- come expands the role of hepatectomy in management of benign and malignant hepatobiliary diseases: analysis of 1222 consecutive patients from a prospective database. Ann Surg. 2004;240:698-708.

3. Shirabe K, Kajiyama K, Harimoto N, Gion T, Tsujita E, Abe T et al. Early Outcome Following Hepatic Resection in Patients Older Than 80 Years of Age. World J Surg. 2009;33:1927-32.

4. Sulpice L, Rayar M, Campillo B, Pery C, Guillaud A, Meunier B, et al. Advanced Age Remains an Achilles Heel for Liver Resections. World J Surg. 2014;38:918-26.

5. Strasberg SM. Nomenclature of hepatic anatomy and resections: a review of the Brisbane 2000 system. J Hepatobiliary Pancreat Surg 2005;12:351-55.

6. Dindo D, Demartines N, Clavien PA. Classification of surgical complications: a new proposal with evaluation in a cohort of 6336 patients and results of a survey. Ann Surg 2004;240:205-13.

7. United Nations World Population Ageing. United Nations, New York, 2002, p 35.

8. Aapro MS, Kohne $\mathrm{CH}$, Cohen HJ, Extermann M. Never too old? Age should not be a barrier to enrollment in cancer clinical trials. Oncologist 2005;10:198-204.

9. Australian bureau of statistics. Census 2011.

10. Menon KV, Al-Mukhtar A, Aldouri A, Prasad RK, Lodge PA, Toogood GJ. Outcomes after major hepatectomy in elderly patients. J Am Coll Surg 2006;203:677-83.
11. Figueras J, Ramos E, Lopez-Ben S, Torras J, Albiol M, Liado L et al. Surgical treatment of liver metastases from colorectal carcinoma in elderly patients: when is it worthwhile? Clin Transl Oncol 2007;9:392-400.

12. Bockhorn M, Sotiropoulos GC, Sgourakis G, Neuhaus JP, Molmenti EP, Lang $\mathrm{H}$ et al. Major liver resections in the elderly- is an aggressive approach justified? Int J Colorectal Dis 2009;24:83-86.

13. De Liguori CN, van Leeuwen $B L$, Ghaneh $P, W u A$, Audisio RA, Poston GJ. Liver resection for colorectal liver metastases in older patients. Crit Rev Oncol Hematol 2008;67:273-78.

14. Mirici-Cappa F, Gramenzi A, Santi V, Zambruni A, Di Micoli A, Frigerio $M$ et al. Treatments for hepatocellular carcinoma in elderly patients are as effective as in younger patients: a 20-year multicentre experience. Gut 2010;59:387-396.

15. Riffat $F, C h u F$, Morris $D L$. Liver resection in octogenarians. HPB 2006;8:206-10.

16. Wu CC. Chen JT, Ho WL, Yeh DC, Tang JS, Liu TJ, et al. Liver resection for hepatocellular carcinoma in octogenarians. Surgery 1999;125: 332-38.

17. Rahbari NN, Koch M, Mehabi A, Weidmann K, Motschall E, Kahlert $C$ et al. Portal triad clamping versus vascular exclusion for vascular control during hepatic resection: a systematic review and metaanalysis. J Gastrointest Surg 2008;13:558-68.

18. Belghiti J, Marty J, Farges O. Technique, hemodynamic monitoring, and indications for vascular clamping during liver resection. Ann Surg 1999;229:369-75.

19. Cunningham JD, Fong Y, Shriver C, Melendez J, Marx WL, Blumgart LH. One hundred consecutive hepatic resections. Blood loss, transfusion, and operative technique. Arch Surg 1994;129:1050-56. 